\title{
Palatability Traits of Sirloin Cap Steaks From Four USDA Quality Grades ${ }^{1}$
}

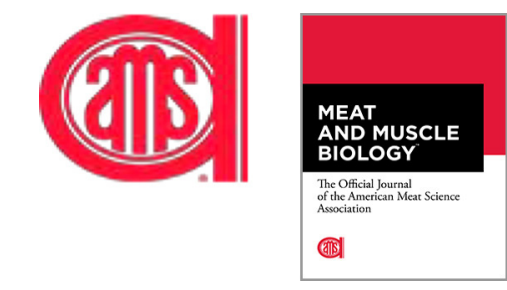

Erin S. Beyer, Keayla M. Harr, Brittany A. Olson, Emily A. Rice, Cassandra K. Jones, Michael D. Chao, Jessie L. Vipham, Morgan D. Zumbaugh, and Travis G. O'Quinn*

Department of Animal Sciences and Industry, Kansas State University, Manhattan, KS 66506, USA

*Corresponding author. Email: travisoquinn@ksu.edu (Travis G. O'Quinn)

${ }^{1}$ Contribution no. 21-249-J of the Kansas Agricultural Experiment Station, Manhattan, KS 66506

\begin{abstract}
Sirloin cap steaks from 4 different USDA quality grades were evaluated to determine the effect of marbling on eating experience. Top sirloin cap steaks $(N=60)$ of 4 different quality grades (Prime, Top Choice, Low Choice, and Select) were evaluated in the current study. Top sirloin butts were collected, and the biceps femoris was removed, trimmed, and sliced into twelve 2.54-cm-thick steaks. The steaks from each subprimal were aged for $28 \mathrm{~d}$ and designated for either trained sensory panels, consumer sensory panels, Warner-Bratzler shear force, or moisture and fat determination. The Prime steaks were rated the highest $(P<0.05)$ for overall liking and were higher $(P<0.05)$ for flavor liking than Low Choice and Select steaks within the consumer panels. However, all quality treatments were similar $(P>0.05)$ in juiciness and tenderness for the consumer panels. Additionally, a similar $(P>0.05)$ percentage of samples from each treatment were rated acceptable for tenderness, juiciness, flavor liking, and overall liking, with each trait having greater than $70 \%$ of samples rated acceptable. Also, Prime steaks were rated the highest $(P<0.05)$ for sustained juiciness and overall tenderness within the trained sensory panels. Similarly, Prime steaks were rated higher $(P<0.05)$ for initial juiciness than the Low Choice and Select treatments but were similar $(P>0.05)$ to Top Choice. These results indicate that USDA quality grades impact the eating quality of sirloin cap steaks, especially within the Prime grade, and could provide an opportunity for refined marketing and added economic value for the cut.
\end{abstract}

Key words: beef, biceps femoris, consumer, marbling, palatability, top sirloin cap steaks

Meat and Muscle Biology 5(1): 31, 1-10 (2021)

doi:10.22175/mmb.12424

Submitted 1 April 2021

Accepted 25 May 2021

\section{Introduction}

The sirloin cap steak is the dorsal portion of the biceps femoris, which is a part of the top sirloin butt (Institutional Meat Purchase Specifications \#184) and is frequently removed from the gluteus medius to be marketed separately (USDA-AMS, 2020). Understanding the impact of marbling on the sirloin cap steak (biceps femoris) eating experience has become increasingly more important because of the rising popularity of the cut, especially in food service. Brazilian steak houses commonly serve a "Coulotte" or "picanha" steak, which are the common trade names often used in restaurants or retail for the sirloin cap steak (Beef2Live, 2020).
This traditional Brazilian cut has slowly migrated not only into US Brazilian steakhouses but also into meal kits and into other retail settings throughout North America (ButcherBox, 2020). This rise in popularity throughout the United States has increased consumer recognition of the cut as well as demand for this beef item, thus supporting the need for a greater understanding of the eating quality of this cut.

The impact of quality grade and marbling has been extensively studied within the middle meats, and research has consistently demonstrated improved eating quality to be associated with increased marbling levels through increased juiciness, tenderness, and flavor (Parrish et al., 1973; Smith et al., 1987; Legako 
et al., 2015; Nyquist et al., 2018; O’Quinn et al., 2018); however, the impact of marbling on other muscles within the carcass has not been as thoroughly evaluated. Understanding the relationship between USDA quality grades or marbling and the eating experience within specific muscles can lead to refined marketing, economic strategies, and higher consumer satisfaction for each cut (Nyquist et al., 2018). The eating experience of different USDA quality grades has been determined for various muscles, including the longissimus lumborum, psoas major, semimembranosus, gluteus medius, infraspinatus, triceps brachii-lateral head, triceps brachii-long head, serratus ventralis, complexus, splenius, rhomboideus, vastus lateralis, rectus femoris, biceps femoris-long head, longissimus dorsi, semitendinosus, spinalis dorsi, supraspinatus, tensor fasciae latae, teres major, vastus medialis, adductor, and longissimus thoracis (Bratcher et al., 2005; Gruber et al., 2006; O'Quinn et al., 2012; Hunt et al., 2014; Legako et al., 2015; Nyquist et al., 2018). Although many other muscles have been studied within different quality grades, the sirloin cap has remained largely ignored.

Although the impact of marbling on the eating quality of the biceps femoris in the round has been evaluated, the biceps femoris long and short heads have been shown to offer different eating experiences in comparison with the sirloin cap (Reuter et al., 2002; Jeremiah et al., 2003b; Hosch et al., 2013). Previous work has demonstrated that the biceps femoris is more tender at the anterior end than the posterior end (Reuter et al., 2002; Jeremiah et al., 2003a; Hosch et al., 2013). Similarly, many differences in tenderness are often found based on anatomical location within the muscle, as found in the biceps femoris, semitendinosus, semimembranosus, and adductor (Reuter et al., 2002; Phelps et al., 2016). Variation in fiber type and collagen content can also occur throughout a muscle and contribute to the different tenderness values and eating characteristics experienced within the same muscle (Hunt and Hedrick, 1977; Klont et al., 1998). Thus, previous work evaluating eating quality related to the biceps femoris from the round may not be representative of the palatability characteristics found within the anterior end of the muscle in the sirloin cap. Therefore, the objective of this study was to determine the effect of USDA quality grade on the eating experience offered by sirloin cap steaks.

\section{Materials and Methods}

The Kansas State University (KSU) Institutional Review Board approved all procedures for use of human subjects in sensory panel evaluations (Institutional Review Board \#7440.6, November 2019).

\section{Sample collection and fabrication}

Samples used in the current study were obtained from the biceps femoris removed from top sirloin butts during fabrication in a previous study, with all details related to product selection outlined by Olson et al. (2019). In brief, beef top sirloin butts ( $N=60$; Institutional Meat Purchasing Specifications \#184; North American Meat Institute, 2014) were collected with equal ratios of 4 different USDA quality grades: Select (slight $^{00}$ to slight ${ }^{100}$ ), Low Choice (small ${ }^{00}$ to small ${ }^{100}$ ), Top Choice (modest $^{00}$ to moderate ${ }^{100}$ ), and Prime (slightly abundant ${ }^{00}$ to abundant ${ }^{100}$ ). Subprimals were selected from a commercial beef processing facility in the Midwest, vacuum sealed individually, and transported back to $\mathrm{KSU}$ under refrigeration $\left(2^{\circ} \mathrm{C}\right.$ to $\left.4^{\circ} \mathrm{C}\right)$ for aging and fabrication. At $4 \mathrm{~d}$ postmortem, the top sirloin butts were fabricated by separating the gluteus medias from the biceps femoris and removing any exterior fat. The sirloin caps were trimmed to less than $0.5-\mathrm{cm}$ fat and sliced into 12 consecutive $2.54-\mathrm{cm}$ steaks perpendicular to the muscle fiber orientation using a cutting guide. Each steak from each primal was randomly assigned a unique 4-digit code. The 4 largest and most posterior steaks were randomly designated for either consumer sensory panels, trained sensory panels, fat and moisture analysis, or Warner-Bratzler shear force (WBSF), with one steak assigned for each analysis. Immediately following fabrication, the steaks were vacuum sealed in 3-mil standard barrier vacuum pouches (PrimeSource, Kansas City, MO) and aged for $28 \mathrm{~d}$ at $2^{\circ} \mathrm{C}$ to $4^{\circ} \mathrm{C}$. After the aging period, all steaks were frozen and stored at $-40^{\circ} \mathrm{C}$ until subsequent analysis.

\section{Warner-Bratzler shear force}

The WBSF of the steaks was determined using the American Meat Science Association (AMSA) WBSF protocol (AMSA, 2015). All steaks were thawed $\left(2^{\circ} \mathrm{C}\right.$ to $\left.4^{\circ} \mathrm{C}\right)$ for $24 \mathrm{~h}$ prior to shear force analysis. The steaks were weighed on a calibrated scale, and the raw weights were recorded for determination of cooking loss percentage. Once weighed, the steaks were cooked on a clamshell grill (Griddler Deluxe, Cuisinart, East Windsor, NJ) set at $177^{\circ} \mathrm{C}$ to an internal temperature of $63^{\circ} \mathrm{C}$ monitored using calibrated ThermoWorks (Salt Lake City, UT) Thermapens Mk4 to allow for the postcooking temperature rise. Next, the samples were removed from the heat source, and the peak temperatures were determined and recorded. A target peak 
temperature of $71^{\circ} \mathrm{C}$ was achieved as an average for each treatment. After cooking, the samples were cooled $\left(2^{\circ} \mathrm{C}\right.$ to $\left.4^{\circ} \mathrm{C}\right)$ overnight. Once chilled, 6 cores $(1.27 \mathrm{~cm})$ were taken from each sample, parallel to the muscle fiber orientation. Each core was sheared perpendicular to the muscle fiber orientation using an Instron testing machine (Model 5569, Instron, Canton, MA) with a crosshead speed of $250 \mathrm{~mm} / \mathrm{min}$ and a load cell of $100 \mathrm{~kg}$. The shear force measurements from all 6 cores were averaged for each sample and presented as average peak force (kilograms).

\section{Moisture and fat determination}

Moisture was determined by the AOAC drying oven method (950.46 and 934.01; AOAC, 1995). Aluminum pans were cleaned, dried at $100^{\circ} \mathrm{C}$ for $30 \mathrm{~min}$, and then weighed and labeled for each sample in duplicate. Prior to homogenization, all external fat and connective tissue was removed from the entire steak sample. Then, samples were diced, frozen in liquid nitrogen, and homogenized using a Waring blender (Waring, Hartford, CT), and stored at $-80^{\circ} \mathrm{C}$ until further analysis. Next, the powdered samples were weighed in duplicate into the corresponding aluminum pans and dried at $100^{\circ} \mathrm{C}$ for $24 \mathrm{~h}$. After being dried, the samples were weighed and recorded. Moisture percentage was determined as the amount of moisture lost during the drying procedure.

Fat percentage was determined by a modified chloroform:methanol extraction method derived from the Folch method (Folch et al., 1957). The samples were weighed and added to the corresponding preweighed $50-\mathrm{mL}$ centrifuge tubes in duplicate. Then, water, chloroform, and methanol were added to each tube using a repeating pipettor. The tubes were shaken and centrifuged at $2,000 \times g$ for $10 \mathrm{~min}$. Next, the top aqueous layer was removed and $4 \mathrm{~mL}$ of the chloroform layer containing the lipid was extracted and added to predried, weighed, and labeled glass disposable tubes. Lastly, the tubes were dried at $100^{\circ} \mathrm{C}$ for $24 \mathrm{~h}$ before being reweighed to determine the percentage of fat. The fat percentage was determined by the amount of weight left after extraction and drying in comparison with the starting weight of the tube and the initial sample weight.

\section{Consumer sensory panels}

Consumers $(N=118)$ were recruited in Manhattan, Kansas, through KSU email and bulletins. The consumers were informed of the monetary compensation (\$20) for their participation on the panel as well as the requirements for a consumer sensory panel. A total of 15 consumer panels were held at KSU and were conducted by KSU representatives. Each panel consisted of 7 to 8 consumers, with 3 panels being conducted simultaneously for a total of 22 to 24 participants at a single time. At the beginning of each panel, the consumers were given water, unsalted crackers, apple juice, utensils, and an electronic tablet (Model 5709 HP Stream 7; Hewlett-Packard, Palo Alto, CA) with the Qualtrics (Version 2417833; Provo, UT) survey corresponding to the panel. The consumers were given verbal, detailed instructions about palate cleansing, filling out the digital ballots, and the meaning of each anchor on the ballots. Prior to evaluation of samples, consumers filled out a basic demographic questionnaire regarding individual and household characteristics. Each consumer was fed one sample from each quality grade treatment in a random order. Samples were evaluated for juiciness, tenderness, flavor liking, and overall liking on 100-point continuous line scales with 0 anchored at extremely tough, extremely dry, and dislike extremely and 100 anchored at extremely tender, extremely juicy, and like extremely. Moreover, consumers evaluated each trait as either acceptable or unacceptable and classified each sample as either "unsatisfactory," "everyday quality," "better than everyday quality," or "premium quality." Each steak was sampled by $7-8$ consumers, with all individual consumer data averaged down to a single value for each steak.

Steaks used for sensory evaluation were thawed $24 \mathrm{~h}$ prior to the starting time of the panel in a $2^{\circ} \mathrm{C}$ to $4^{\circ} \mathrm{C}$ cooler. Prior to cooking, a raw weight was taken for each steak. The steaks were cooked using identical procedures to those described previously for WBSF evaluation. Following cooking, the steaks were sliced using a slicing guide into $2.5-\mathrm{cm}$ thick $\times 1-\mathrm{cm} \times 1-\mathrm{cm}$ cuboids, and 2 pieces were served immediately to consumers. Samples were identified to consumers using a unique 4-digit code. Following the conclusion of the panels, consumer ratings were averaged to produce a single value for each trait for each sample.

\section{Trained sensory panels}

Sensory panelists were trained according to the AMSA sensory guidelines (AMSA, 2015). Panelists were recruited from a population of trained sensory panelists with more than $100 \mathrm{~h}$ of previous experience. Prior to panels, panelists were familiarized with scales and trained in 4 training sessions in the week immediately preceding the start of panels using the methods, scales, and anchors described by Lucherk et al. (2016) 
and Vierck et al. (2018). Trained sensory panels consisted of 8 panelists who were fed 2 samples from each quality grade treatment in a random order.

Cooking procedures for trained sensory panels followed the procedures outlined for WBSF and consumer sensory evaluation. Samples were sliced using a slicing guide into $2.5-\mathrm{cm}$ thick $\times 1-\mathrm{cm} \times 1-\mathrm{cm}$ cuboids, with 2 cuboids served to each panelist for each sample. At the beginning of each panel, the panelists were given a representative sirloin cap steak warm-up sample to allow for panel calibration and to prevent panelist drift. Panelists evaluated each sample for initial juiciness, sustained juiciness, myofibrillar tenderness, connective tissue amount, overall tenderness, beef flavor intensity, lipid flavor intensity, and off-flavor intensity on 0 - to 100 -point line scales. Anchors set at 0 were labeled as extremely dry, extremely tough, none, and extremely bland. Midpoint (50) anchors were labeled as neutral points of neither juicy nor dry and neither tough nor tender. At 100, anchors were labeled as extremely juicy, extremely tender, abundant, and extremely intense. Panelists were served in individual sensory booths under low-intensity ( $<107.64$ lumens) red incandescent lights. During each session, panelists were given an electronic tablet (Model 5709 HP Stream 7; Hewlett-Packard) with the electronic survey ballot, deionized water, apple slices, and unsalted crackers for palate cleansers as well as an expectorant cup and napkins.

\section{Statistical analysis}

The statistical analysis was conducted using SAS (Version 9.4; SAS Institute, Inc., Cary, NC) PROC GLIMMIX, with treatment comparisons considered significant with an $\alpha$ of 0.05 . Subprimal served as the experimental unit, with data analyzed using a mixed model as a completely randomized design. For all analyses, quality grade treatment served as a fixed effect, and for sensory panel data, panel time served as a random effect. All acceptability data were analyzed with a model that included a binomial error distribution to allow for the yes/no questions. PROC FREQ was used to summarize the demographic data. The KenwardRoger adjustment was used in all analyses.

\section{Results}

The demographic profile of the 118 consumers is summarized in Table 1 . The majority of consumers were female $(65.3 \%)$ with some college education $(57.6 \%)$. Almost the entire sampling demographic set
Table 1. Demographic characteristics of consumers $(N=118)$ who participated in consumer sensory panels

\begin{tabular}{|c|c|c|}
\hline Characteristic & Response & $\begin{array}{c}\text { Percentage of } \\
\text { Consumers }\end{array}$ \\
\hline \multirow[t]{2}{*}{ Gender } & Male & 34.8 \\
\hline & Female & 65.3 \\
\hline \multirow[t]{6}{*}{ Household Size } & 1 person & 6.8 \\
\hline & 2 people & 10.2 \\
\hline & 3 people & 8.5 \\
\hline & 4 people & 37.3 \\
\hline & 5 people & 27.1 \\
\hline & 6 or more people & 5.1 \\
\hline \multirow[t]{4}{*}{ Educational Level } & High school graduate & 31.4 \\
\hline & $\begin{array}{l}\text { Some college/ } \\
\text { technical school }\end{array}$ & 57.6 \\
\hline & College graduate & 6.8 \\
\hline & Postcollege graduate & 4.2 \\
\hline \multirow[t]{2}{*}{ Marital Status } & Married & 5.1 \\
\hline & Single & 94.9 \\
\hline \multirow[t]{5}{*}{ Age } & Under 20 & 32.6 \\
\hline & 20 to 29 & 57.6 \\
\hline & 30 to 39 & 3.4 \\
\hline & 40 to 49 & 0.9 \\
\hline & 50 to 59 & 2.5 \\
\hline \multirow[t]{6}{*}{ Ethnic Origins } & African American & 1.7 \\
\hline & Asian & 4.2 \\
\hline & Caucasian/White & 83.1 \\
\hline & Latino & 5.9 \\
\hline & Mixed race & 3.4 \\
\hline & Native American & 1.7 \\
\hline \multirow[t]{8}{*}{ Income } & Under $\$ 25,000$ & 13.6 \\
\hline & $\$ 25,000$ to $\$ 34,999$ & 7.6 \\
\hline & $\$ 35,000$ to $\$ 49,999$ & 3.4 \\
\hline & $\$ 50,000$ to $\$ 74,999$ & 18.6 \\
\hline & $\$ 75,000$ to $\$ 99,999$ & 15.3 \\
\hline & $\$ 100,000$ to $\$ 149,999$ & 23.7 \\
\hline & $\$ 150,000$ to $\$ 199,999$ & 7.6 \\
\hline & $>\$ 199,999$ & 10.1 \\
\hline \multirow{9}{*}{$\begin{array}{l}\text { Most Important Palatability } \\
\text { Trait When Consuming Beef } \\
\text { PreferredDegree of Doneness } \\
\text { When Consuming Beef }\end{array}$} & Tenderness & 33.9 \\
\hline & Juiciness & 11.9 \\
\hline & Flavor & 54.2 \\
\hline & Rare & 8.5 \\
\hline & Medium rare & 49.2 \\
\hline & Medium & 22.9 \\
\hline & Medium well & 16.1 \\
\hline & Well done & 2.5 \\
\hline & Very well done & 0.9 \\
\hline \multirow[t]{3}{*}{ Weekly Beef Consumption } & 1 to 5 times & 56.8 \\
\hline & 6 to 10 times & 27.1 \\
\hline & 11 or more times & 16.1 \\
\hline
\end{tabular}


were single (94.9\%) and fell within the under $20(32.6 \%)$ or between 20 and $29(57.6 \%)$ age groups. Additionally, almost all income brackets were represented within the demographic set. Moreover, the majority of consumers listed flavor $(54.2 \%)$ as the most important palatability characteristic, followed by tenderness $(33.9 \%)$. Also, medium rare $(49.2 \%)$ and medium $(22.9 \%)$ were the favored degrees of doneness. Lastly, the majority of the consumers consumed beef between 1 and 5 times a week (56.8\%).

The consumer sensory panel rating data are presented in Table 2. All quality treatments were similar $(P>0.05)$ in juiciness and tenderness. Moreover, Prime steaks had a higher $(P<0.05)$ flavor liking rating than either Low Choice or Select treatments but were similar $(P>0.05)$ to Top Choice steaks. Additionally, Prime steaks were rated higher $(P<0.05)$ than all other treatments for overall liking.

Table 3 shows the consumer acceptability data. A similar $(P>0.05)$ percentage of samples from each treatment were rated acceptable for tenderness, juiciness, flavor liking, and overall liking, with each trait having greater than $70 \%$ of samples rated acceptable (Table 3). The percentages of samples classified as each of the 4 different quality levels are listed in Table 4. Low Choice steaks were more frequently $(P<0.05)$ identified as everyday quality in comparison with Prime but had a similar $(P>0.05)$ percentage as the remaining treatments. Additionally, all 4 treatments had a similar $(P>0.05)$ percentage of samples classified as unsatisfactory, better than everyday quality, and premium quality.

Table 2. Least-squares means for beef palatability ratings ${ }^{1}$ for beef sirloin cap steaks from 4 quality levels for consumer $(N=118)$ sensory panels

\begin{tabular}{lcccc}
\hline \hline Quality Grade & Juiciness & Tenderness & Flavor & Overall Liking \\
\hline Prime & 67.9 & 68.4 & $64.7^{\mathrm{a}}$ & $68.9^{\mathrm{a}}$ \\
Top Choice $^{2}$ & 64.6 & 65.6 & $61.7^{\mathrm{ab}}$ & $63.6^{\mathrm{b}}$ \\
Low Choice & 61.9 & 65.9 & $57.9^{\mathrm{b}}$ & $61.0^{\mathrm{b}}$ \\
Select & 68.5 & 63.9 & $56.9^{\mathrm{b}}$ & $59.6^{\mathrm{b}}$ \\
SEM $^{3}$ & 2.02 & 2.57 & 2.46 & 2.18 \\
$\boldsymbol{P}$ Value & 0.07 & 0.46 & 0.04 & $<0.01$ \\
\hline
\end{tabular}

${ }^{1}$ Sensory scores: $0=$ extremely dry/tough/dislike; $50=$ neither dry nor juicy, neither tough nor tender, neither like nor dislike; $100=$ extremely juicy/tender/like extremely.

${ }^{2}$ Marbling scores of modest ${ }^{00}$ to moderate ${ }^{100}$.

${ }^{3}$ Standard error (largest) of the least-squares means. SEM $=$ standard error of the mean.

${ }^{\mathrm{a}, \mathrm{b}}$ Least-squares means within the same column without a common superscript differ $(P<0.05)$.
Table 3. Percentage of beef sirloin cap steaks from 4 quality levels rated as acceptable for juiciness, tenderness, flavor, and overall liking by consumers $(N=118)$

\begin{tabular}{lcccc}
\hline \hline Quality Grade & Juiciness & Tenderness & Flavor & Overall \\
\hline Prime & 83.9 & 89.2 & 78.6 & 87.7 \\
Top Choice $^{1}$ & 74.5 & 82.2 & 71.2 & 84.4 \\
Low Choice & 76.2 & 82.2 & 75.1 & 75.0 \\
Select & 82.2 & 86.2 & 79.4 & 77.6 \\
SEM $^{2}$ & 0.26 & 0.41 & 0.28 & 0.30 \\
$\boldsymbol{P}$ Value & 0.24 & 0.34 & 0.49 & 0.06 \\
\hline
\end{tabular}

${ }^{1}$ Marbling scores of modest ${ }^{00}$ to moderate ${ }^{100}$.

${ }^{2}$ Standard error (largest) of the least-squares means. SEM $=$ standard error of the mean.

Table 4. Percentage of beef sirloin cap steaks from 4 quality grades rated as various perceived quality levels by consumers $(N=118)$

\begin{tabular}{lcccc}
\hline \hline $\begin{array}{l}\text { Quality } \\
\text { Grade }\end{array}$ & Unsatisfactory & $\begin{array}{c}\text { Everyday } \\
\text { Quality }\end{array}$ & $\begin{array}{c}\text { Better Than } \\
\text { Everyday } \\
\text { Quality }\end{array}$ & $\begin{array}{c}\text { Premium } \\
\text { Quality }\end{array}$ \\
\hline $\begin{array}{l}\text { Prime } \\
\text { Top }\end{array}$ & 8.0 & $36.8^{\mathrm{b}}$ & 39.3 & 15.0 \\
Choice & 10.4 & $49.6^{\mathrm{ab}}$ & 27.4 & 11.6 \\
Low & 11.3 & $57.3^{\mathrm{a}}$ & 23.1 & 7.4 \\
Choice & & & & \\
Select & 16.2 & $47.9^{\mathrm{ab}}$ & 29.9 & 4.9 \\
SEM $^{2}$ & 0.36 & 0.19 & 0.22 & 0.43 \\
$\boldsymbol{P}$ Value & 0.26 & 0.03 & 0.06 & 0.07 \\
\hline
\end{tabular}

${ }^{1}$ Marbling scores of modest ${ }^{00}$ to moderate ${ }^{100}$.

${ }^{2}$ Standard error (largest) of the least-squares means. SEM = standard error of the mean.

${ }^{\mathrm{a}, \mathrm{b}}$ Least-squares means within the same column without a common superscript differ $(P<0.05)$.

Table 5 presents the trained sensory panel results. Prime steaks were rated higher $(P<0.05)$ for initial juiciness than the Low Choice and Select treatments but were similar $(P>0.05)$ to Top Choice. Similarly, Prime steaks had higher $(P<0.05)$ sustained juiciness scores than all other treatments. Also, Top Choice steaks were rated higher $(P<0.05)$ than the Select samples for the same trait. Prime steaks were rated as more tender $(P<0.05)$ overall than all other treatments, with no differences $(P>0.05)$ for overall tenderness found among the other treatments. Lastly, Prime had a stronger $(P<0.05)$ beef flavor intensity than Select steaks. No differences $(P>0.05)$ were found among any of the treatments for myofibrillar tenderness, connective tissue amount, or off-flavor intensity ratings. 
Table 5. Trained sensory panel least-squares means for beef quality ratings ${ }^{1}$ of beef sirloin cap steaks from 4 quality levels

\begin{tabular}{|c|c|c|c|c|c|c|c|}
\hline $\begin{array}{l}\text { Quality } \\
\text { Grade }\end{array}$ & $\begin{array}{c}\text { Initial } \\
\text { Juiciness }\end{array}$ & $\begin{array}{c}\text { Sustained } \\
\text { Juiciness }\end{array}$ & $\begin{array}{l}\text { Myofibrillar } \\
\text { Tenderness }\end{array}$ & $\begin{array}{c}\text { Connective } \\
\text { Tissue } \\
\text { Amount }\end{array}$ & $\begin{array}{c}\text { Overall } \\
\text { Tenderness }\end{array}$ & $\begin{array}{l}\text { Beef Flavor } \\
\text { Intensity }\end{array}$ & $\begin{array}{l}\text { Off- Flavor } \\
\text { Intensity }\end{array}$ \\
\hline Prime & $74.9^{\mathrm{a}}$ & $69.8^{\mathrm{a}}$ & 81.1 & 5.8 & $79.0^{\mathrm{a}}$ & $48.1^{\mathrm{a}}$ & 0.1 \\
\hline Top Choice ${ }^{2}$ & $70.7^{\mathrm{ab}}$ & $64.4^{\mathrm{b}}$ & 77.3 & 6.9 & $74.0^{\mathrm{b}}$ & $47.0^{\mathrm{ab}}$ & 0.7 \\
\hline Low Choice & $67.0^{\mathrm{bc}}$ & $60.8^{\mathrm{bc}}$ & 77.1 & 7.9 & $73.9^{\mathrm{b}}$ & $46.5^{\mathrm{ab}}$ & 0.8 \\
\hline Select & $65.9^{\mathrm{c}}$ & $59.2^{\mathrm{c}}$ & 77.0 & 6.8 & $73.9^{\mathrm{b}}$ & $44.9^{\mathrm{b}}$ & 0.2 \\
\hline $\mathrm{SEM}^{3}$ & 1.55 & 1.72 & 1.35 & 0.77 & 1.48 & 0.90 & 0.42 \\
\hline$P$ Value & $<0.01$ & $<0.01$ & 0.10 & 0.22 & 0.02 & 0.05 & 0.60 \\
\hline
\end{tabular}

${ }^{1}$ Sensory scores: $0=$ extremely dry/tough/bland/none, $50=$ neither juicy/dry/tough/tender, $100=$ extremely juicy/tender/abundant/intense.

${ }^{2}$ Marbling scores of modest ${ }^{00}$ to moderate ${ }^{100}$.

${ }^{3}$ Standard error (largest) of the least-squares means. SEM $=$ standard error of the mean.

${ }^{\mathrm{a}-\mathrm{C}}$ Least-squares means within the same column without a common superscript differ $(P<0.05)$.

Lastly, the WBSF values, cooking loss percentages, moisture percentages, and fat percentages are presented in Table 6 . The WBSF values were similar $(P>0.05)$ among all the treatments, with all mean values at $3.1 \mathrm{~kg}$ or less. Similarly, the cooking loss percentages were similar $(P>0.05)$ among all the treatments, with each losing between $19 \%$ and $21.5 \%$ on average. As expected, the fat percentage increased $(P<0.05)$ as quality grade increased (Prime $>$ Top Choice $=$ Low Choice $>$ Select $)$. Moreover, the Select treatment had a higher $(P<0.05)$ moisture percentage than either Low Choice or Top Choice.

\section{Discussion}

Overall, marbling impacted panelist eating experience within the sirloin cap muscle, although not to the

Table 6. Least-squares means for moisture percentage, fat percentage, Warner-Bratzler shear force (WBSF), and cooking loss percentage of beef sirloin cap steaks from 4 quality levels

\begin{tabular}{|c|c|c|c|c|}
\hline Quality Grade & Moisture, $\%$ & Fat, \% & WBSF, kg & Cooking Loss, ${ }^{1} \%$ \\
\hline Prime & $72.9^{\mathrm{ab}}$ & $10.7^{\mathrm{a}}$ & 2.7 & 19.0 \\
\hline Top Choice ${ }^{2}$ & $71.6^{b}$ & $8.0^{\mathrm{b}}$ & 2.7 & 21.2 \\
\hline Low Choice & $71.6^{\mathrm{b}}$ & $7.2^{\mathrm{b}}$ & 2.6 & 21.2 \\
\hline Select & $74.9^{\mathrm{a}}$ & $5.7^{\mathrm{c}}$ & 3.1 & 20.8 \\
\hline SEM $^{3}$ & 0.82 & 0.41 & 0.19 & 0.69 \\
\hline$P$ Value & 0.02 & $<0.01$ & 0.24 & 0.08 \\
\hline \multicolumn{5}{|c|}{${ }^{1}$ Cooking loss $=1-($ cooked weight $/$ raw weight $) \times 100$. } \\
\hline \multicolumn{5}{|c|}{${ }^{2}$ Marbling scores of modest ${ }^{00}$ to moderate ${ }^{100}$} \\
\hline \multicolumn{5}{|c|}{$\begin{array}{l}{ }^{3} \text { Standard error (largest) of the least-squares means. SEM = standard } \\
\text { error of the mean. }\end{array}$} \\
\hline
\end{tabular}

same extent as in many other muscles (Smith et al., 1987; Legako et al., 2015; McKillip et al. 2017; O'Quinn et al., 2018). Prime steaks had higher juiciness and tenderness ratings within the trained sensory results, although the same was not observed with consumer sensory panel ratings or WBSF. However, despite identifying similarities in tenderness and juiciness, consumers liked Prime steaks better overall than lower-grading treatments. It is also noteworthy that in both consumer and trained sensory panels, Prime had a higher rating for beef flavor traits and flavor liking scores than lower-grading products. Conversely, Select samples had lower juiciness characteristics for trained sensory panelists than both Prime and Top Choice samples but differed only from Prime for traits evaluated by consumers. These results provide some evidence that marbling impacts top sirloin cap steak palatability, although differences in eating quality at adjacent grades were not always evident.

It is important to note that the consumers utilized in the current study were not a representative demographic mix of the US population. The consumers in the current study tended to be younger and less educated and were a higher percentage female than the US population. This is reflective of the high number of college students who participated in the current consumer panels. Previous authors have reported that demographic differences have little impact on consumer palatability ratings of beef steaks (Mehaffey et al., 2009; Reicks et al., 2011), although the current results should be evaluated in the context of the panelists' demographic profile.

Despite limited previous work evaluating the impact of marbling on the sirloin cap muscle, similar trends related to marbling in other muscles have been reported. Numerous prior reports have detailed this 
relationship for the longissimus dorsi and other middle meats, with many authors reporting improved palatability as marbling score or USDA quality increased (Smith et al., 1987; O'Quinn et al., 2012; Legako et al., 2015, 2016; Nyquist et al., 2018). Although it seems reasonable to believe this effect would transcend to all muscles, each muscle does not deposit marbling or fat the same way and has a variety of other characteristics known to impact eating quality, such as variation in connective tissue amount. Thus, the palatability traits of some muscles have been found to be only minimally impacted by an increase in quality grade. The eating quality of many muscles found in the round and chuck, including the semimembranosus, semitendinosus, triceps brachii, and the posterior end of the biceps femoris, have repeatedly been shown to be only minimally impacted by marbling content (Smith et al., 1985; Kukowski et al., 2004; Hunt et al., 2014). Additionally, many of these same muscles have been shown to have comparatively high concentrations of both total and insoluble collagen content (Jeremiah et al., 2003a). Similarly, marbling content has also been shown to have little to no impact on the eating quality of the psoas major (Shackelford et al., 1995; Legako et al., 2015; O'Quinn et al., 2015). Unlike many of the muscles of the round and chuck, the psoas major has one of the lowest amounts of total and insoluble collagen in the carcass (McKeith et al., 1985; Jeremiah et al., 2003a). Collectively, this provides evidence of a "Goldilocks Window" for marbling to have a significant impact on eating quality in relation to the amount of connective tissue of the muscle. This "Goldilocks Window" can be defined as the range of connective tissue of a given muscle in which marbling has a significant impact on palatability traits. Muscles with a high connective tissue amount, such as those from the round and chuck, have the positive impact of marbling on eating quality "overshadowed" by the negative impact of the high levels of connective tissue. Muscles, such as the psoas major, with extremely low connective tissue amounts also have the impact of marbling "overshadowed" by the lack of connective tissue and the resulting lack of a negative tenderness impact that the connective tissue has in other muscles. Thus, muscles with some, but not too much, connective tissue such as the longissimus lumborum and longissimus thoracis fall within this "Goldilocks Window" of connective tissue in which marbling can have a significant impact on eating quality.

The sirloin cap has previously been shown to rank 15th and 13th for total collagen and insoluble collagen content, respectively, out of 33 major muscle groups in the carcass (Jeremiah et al., 2003a). These authors reported the collagen content of the sirloin cap to be most similar to the brisket and gluteus medius (Jeremiah et al., 2003a). Additionally, the sirloin cap was also shown to have a similar amount of both total and insoluble collagen content as the posterior portion of the biceps femoris located within the round (Jeremiah et al., 2003a). However, uniquely, the sirloin cap was also reported to have one of the greatest variances associated with collagen content of the 33 muscles evaluated. This provides evidence that, although this cut may have a high collagen content, there remains significant variation in connective tissue amount among sirloin cap muscles. This was further supported by the same authors, who reported the sirloin cap had the greatest amount of variation in trained sensory panel connective tissue scores of all 33 muscles evaluated, providing additional evidence of the amount of variation in connective tissue within this muscle (Jeremiah et al., 2003b). Although the current work only evaluated the sirloin cap muscle, our results may indicate that the increased connective tissue amount of this muscle is enough to minimize the impact of marbling on palatability in most cases. Additionally, the relatively low amount of variation in fat percentage observed among the quality grade treatments in the current study may have also contributed to the observed results.

Although few authors have evaluated the impact of marbling on the eating quality of the sirloin cap, many have evaluated this relationship within the posterior end of the biceps femoris, or bottom round. Overall, marbling has been repeatedly shown to have little to no impact on the palatability traits of the biceps femoris. Smith et al. (1985) evaluated the eating quality of bottom round steaks of A maturity carcasses and found no differences in palatability ratings and shear force values as marbling scores increased from practically devoid (USDA Standard) to moderately abundant (USDA Prime). Likewise, Nelson et al. (2004) found no differences in the palatability traits evaluated among bottom round steaks from Top Choice (modest and moderate marbling scores), Choice, and Select quality grades. Conversely, Nyquist et al. (2018) reported an effect of marbling on the tenderness, juiciness, and flavor of bottom round steaks, with increased ratings as quality grade increased from Select to Choice to Prime. However, the authors' conclusions were based on a lack of a significant interaction between quality grade and muscle in a study in which they evaluated 9 different muscle groups. Thus, these authors did not stratify the quality grade effect by muscle, making it difficult to glean the impact of marbling on only the 
biceps femoris. These authors also reported less fat in the biceps femoris for the Choice and Select grades than was observed in the current study (Nyquist et al., 2018). Coupled with these previous works, our results would indicate that the impact of marbling on the biceps femoris in the sirloin cap differs from the impact that it has in the bottom round.

Similar results have also been reported for the other muscle located within the beef top sirloin butt: the gluteus medius. Most previous authors have reported quality grade to have no impact on the palatability traits of the gluteus medius. Olson et al. (2019) reported no differences in the tenderness, juiciness, flavor, and overall liking scores of consumers when evaluating gluteus medius steaks ranging in quality grade from Select to Prime. Similar results have been reported from the 2 most recent "Beef Tenderness Surveys" that have shown no impact of quality grade on gluteus medius palatability, with steaks ranging from Prime to Select (Guelker et al., 2013; Martinez et al., 2017). These results are also in agreement with previous works that allowed consumers to prepare steaks inhome, which has demonstrated no impact of quality grade on gluteus medius palatability (Neely et al., 1998; Savell et al., 1999). Our results would indicate that quality grade has an impact on eating quality of the biceps femoris in the sirloin, which differs from the impact of quality grade on the gluteus medius.

\section{Conclusions}

Overall, USDA quality grades have an impact on the eating experience of sirloin cap steaks, especially within the Prime grade. Therefore, continuing to market sirloin caps of increased quality grades with associated premiums is justified. Although the industry mostly utilizes sirloin cap steaks in food service, there is an opportunity to broaden the marketing and branding of sirloin cap steaks to highlight the differences due to quality grades. Taking strides toward marketing sirloin cap steaks with quality grades listed could be a way to add value while both helping the meat industry and providing another steak option for consumers at the retail level.

\section{Acknowledgments}

Appreciation is expressed to the students enrolled in the fall 2018 course-based undergraduate research project in the Department of Animal Sciences \& Industry at KSU. Their assistance with fabrication, shear force analysis, and taste panel coordination was vital to the success of this project.

\section{Literature Cited}

AMSA. 2015. Research guidelines for cookery, sensory evaluation, and instrumental tenderness measurements of meat. 2nd ed. American Meat Science Association, Champaign, IL.

AOAC. 1995. Removal of moisture. Official method 8.2.1.1. 16th ed. AOAC, Arlington, VA.

Beef2Live. 2020. Picanha. https://beef2live.com/story-picanhabrazil-beef-cut-137-107632. (Accessed 7 December 2020.)

Bratcher, C. L., D. D. Johnson, R. C. Littell, and B. L. Gwartney. 2005. The effects of quality grade, aging, and location within muscle on Warner-Bratzler shear force in beef muscles of locomotion. Meat Sci. 70:279-284. https://doi.org/10.1016/ j.meatsci.2005.01.013.

ButcherBox. 2020. Don't be fooled by the fancy name, coulotte is a cut everyone can enjoy. https://www.butcherbox.com/roam/ inside-the-box/dont-be-fooled-by-the-fancy-name-coulotteis-a-cut-everyone-can-enjoy/. (Accessed 6 December 2020.)

Folch, J., M. Lees, and G. H. Sloane Stanley. 1957. A simple method for the isolation and purification of total lipids from animal tissues. J. Biol. Chem. 266:497-509.

Gruber, S. L., J. D. Tatum, J. A. Scanga, P. L. Chapman, G. C. Smith, and K. E. Belk. 2006. Effects of postmortem aging and USDA quality grade on Warner-Bratzler shear force values of seventeen individual beef muscles. J. Anim. Sci. 84:3387-3396. https://doi.org/10.2527/jas.2006-194.

Guelker, M. R., A. N. Haneklaus, J. C. Brooks, C. C. Carr, R. J. Delmore, Jr., D. B. Griffin, D. S. Hale, K. B. Harris, G. G. Mafi, D. D. Johnson, C. L. Lorenzen, R. J. Maddock, J. N. Martin, R. K. Miller, C. R. Raines, D. L. VanOverbeke, L. L. Vedral, B. E. Wasser, and J. W. Savell. 2013. National Beef Tenderness Survey-2010: Warner-Bratzler shear force values and sensory panel ratings for beef steaks from United States retail and food service establishments. J. Anim. Sci. 91:1005-1014. https://doi.org/10.2527/jas.20125785.

Hosch, J. J., K. Varnold, L. S. Senaratne-Lenagala, M. E. Semler, M. D. Chao, and C. R. Calkins. 2013. An evaluation of the extended sirloin cap coulotte. 2013 Nebraska Beef Cattle Report. University of Nebraska - Lincoln.

Hunt, M. R., A. J. Garmyn, T. G. O’Quinn, C. H. Corbin, J. F. Legako, R. J. Rathmann, J. C. Brooks, and M. F. Miller. 2014. Consumer assessment of beef palatability from four beef muscles from USDA Choice and Select graded carcasses. Meat Sci. 98:1-8. https://doi.org/10.1016/j.meatsci.2014.04.004.

Hunt, M. C., and H. B. Hedrick. 1977. Profile of fiber types and related properties of five bovine muscles. J. Food Sci. 42:513-517. https://doi.org/10.1111/j.1365-2621.1977. tb01535.x.

Jeremiah, L. E., M. E. R. Dugan, J. L. Aalhus, and L. L. Gibson. 2003a. Assessment of the chemical and cooking properties of the major beef muscles and muscle groups. Meat Sci. 65:985-992. https://doi.org/10.1016/S0309-1740(02)00308-X. 
Jeremiah, L. E., L. L. Gibson, J. L. Aalhus, and M. E. R. Dugan. 2003b. Assessment of palatability attributes of the major beef muscles. Meat Sci. 65:949-958. https://doi.org/10.1016/ S0309-1740(02)00307-8.

Klont, R. E., L. Brocks, and G. Eikelenboom. 1998. Muscle fibre type and meat quality. Meat Sci. 49:S219-S229. https://doi. org/10.1016/S0309-1740(98)90050-X.

Kukowski, A. C., R. J. Maddock, and D. M. Wulf. 2004. Evaluating consumer acceptability of various muscles from the beef chuck and rib. J. Anim. Sci. 82:521-525. https://doi.org/10. 2527/2004.822521x.

Legako, J. F., J. C. Brooks, T. G. O’Quinn, T. D. J. Hagan, R. Polkinghorne, L. J. Farmer, and M. F. Miller. 2015. Consumer palatability scores and volatile beef flavor compounds of five USDA quality grades and four muscles. Meat Sci. 100:291-300. https://doi.org/10.1016/j.meatsci. 2014.10.026.

Legako, J. F., T. T. N. Dinh, M. F. Miller, K. Adhikari, and J. C. Brooks. 2016. Consumer palatability scores, sensory descriptive attributes, and volatile compounds of grilled beef steaks from three USDA Quality Grades. Meat Sci. 112:77-85. https://doi.org/10.1016/j.meatsci.2015.10.018.

Lucherk, L. W., T. G. O’Quinn, J. F. Legako, R. J. Rathmann, J. C. Brooks, and M. F. Miller. 2016. Consumer and trained panel evaluation of beef strip steaks of varying marbling and enhancement levels cooked to three degrees of doneness. Meat Sci. 122:145-154. https://doi.org/10.1016/j.meatsci. 2016.08.005.

Martinez, H. A., A. N. Arnold, J. C. Brooks, C. C. Carr, K. B. Gehring, D. B. Griffin, D. S. Hale, G. G. Mafi, D. D. Johnson, C. L. Lorenzen, R. J. Maddock, R. K. Miller, D. L. VanOverbeke, B. E. Wasser, and J. W. Savell. 2017. National Beef Tenderness Survey-2015: Palatability and shear force assessments of retail and foodservice beef. Meat Muscle Biol. 1:138-148. https://doi.org/10.22175/mmb2017.05.0028.

McKeith, F. K., D. L. DeVol, R. S. Miles, P. J. Bechtel, and T. R. Carr. 1985. Chemical and sensory properties of thirteen major beef muscles. J. Food Sci. 50:869-872. https://doi.org/10. 1111/j.1365-2621.1985.tb12968.x.

McKillip, K. V., A. K. Wilfong, J. M. Gonzalez, T. A. Houser, J. A. Unruh, E. A. E. Boyle, and T. G. O'Quinn. 2017. Sensory evaluation of enhanced beef strip loin steaks cooked to 3 degrees of doneness. Meat Muscle Biol. 1:227-241. https:// doi.org/10.22175/mmb2017.06.0033

Mehaffey, J. M., J. C. Brooks, R. J. Rathmann, E. M. Alsup, J. P. Hutcheson, W. T. Nichols, M. N. Streeter, D. A. Yates, B. J. Johnson, and M. F. Miller. 2009. Effect of feeding zilpaterol hydrochloride to beef and calf-fed Holstein cattle on consumer palatability ratings. J. Anim. Sci. 87:3712-3721. https://doi. org/10.2527/jas.2009-1837.

Neely, T. R., C. L. Lorenzen, R. K. Miller, J. D. Tatum, J. W. Wise, J. F. Taylor, M. J. Buyck, J. O. Reagan, and J. W. Savell. 1998. Beef customer satisfaction: role of cut, USDA quality grade, and city on in-home consumer ratings. J. Anim. Sci. 76:10271033. https://doi.org/10.2527/1998.7641027x.

Nelson, J. L., H. G. Dolezal, F. K. Ray, and J. B. Morgan. 2004. Characterization of certified Angus beef steaks from the round, loin, and chuck. J. Anim. Sci. 82:1437-1444.https:// doi.org/10.2527/2004.8251437x.
North American Meat Institute. 2014. The meat buyer's guide. 8th ed. North American Meat Institute, Washington, DC.

Nyquist, K. M., T. G. O'Quinn, L. N. Drey, L. W. Lucherk, J. C. Brooks, M. F. Miller, and J. F. Legako. 2018. Palatability of beef chuck, loin, and round muscles from three USDA quality grades. J. Anim. Sci. 96:4276-4292. https:// doi.org/10.1093/jas/sky305.

Olson, B. A., E. A. Rice, L. L. Prill, L. N. Drey, J. M. Gonzalez, J. L. Vipham, M. D. Chao, and T. G. O'Quinn. 2019. Evaluation of beef top sirloin steaks of four quality grades cooked to three degrees of doneness. Meat Muscle Biol. 3:399-410. https:// doi.org/10.22175/mmb2019.07.0022.

O'Quinn, T. G., J. C. Brooks, and M. F. Miller. 2015. Consumer assessment of beef tenderloin steaks from various USDA quality grades at 3 degrees of doneness. J. Food Sci. 80: S444-S449. https://doi.org/10.1111/1750-3841.12775.

O’Quinn, T. G., J. C. Brooks, R. J. Polkinghorne, A. J. Garmyn, B. J. Johnson, J. D. Starkey, R. J. Rathmann, and M. F. Miller. 2012. Consumer assessment of beef strip loin steaks of varying fat levels. J. Anim. Sci. 90:626-634. https://doi. org/10.2527/jas.2011-4282.

O’Quinn, T. G., J. F. Legako, J. C. Brooks, and M. F. Miller. 2018. Evaluation of the contribution of tenderness, juiciness, and flavor to the overall consumer beef eating experience. Transl. Anim. Sci. 2:26-36. https://doi.org/10.1093/tas/ txx008.

Parrish, F. C., Jr., D. G. Olson, B. E. Miner, and R. E. Rust. 1973. Effect of degree of marbling and internal temperature of doneness on beef rib steaks. J. Anim. Sci. 37:430-434. https://doi. org/10.2527/jas 1973.372430x.

Phelps, K. J., J. S. Drouillard, M. B. Silva, L. D. F. Miranda, S. M. Ebarb, C. L. Van Bibber-Krueger, T. G. O'Quinn, and J. M. Gonzalez. 2016. Effect of extended postmortem aging and steak location on myofibrillar protein degradation and Warner-Bratzler shear force of beef M. semitendinosus steaks. J. Anim. Sci. 94:412-423. https://doi.org/10.2527/jas.20159862.

Reicks, A. L., J. C. Brooks, A. J. Garmyn, L. D. Thompson, C. L. Lyford, and M. F. Miller. 2011. Demographics and beef preferences affect consumer motivation for purchasing fresh beef steaks and roasts. Meat Sci. 87:403-411. https://doi.org/10. 1016/j.meatsci.2010.11.018.

Reuter, B. J., D. M. Wulf, and R. J. Maddock. 2002. Mapping intramuscular tenderness variation in four major muscles of the beef round. J. Anim. Sci. 80:2594-2599. https://doi.org/10. 1093/ansci/80.10.2594.

Savell, J. W., C. L. Lorenzen, T. R. Neely, R. K. Miller, J. D. Tatum, J. W. Wise, J. F. Taylor, M. J. Buyck, and J. O. Reagan. 1999. Beef customer satisfaction: cooking method and degree of doneness effects on the top sirloin steak. J. Anim. Sci. 77:645-652. https://doi.org/10.2527/1999.773645x.

Shackelford, S. D., T. L. Wheeler, and M. Koohmaraie. 1995. Relationship between shear force and trained sensory panel tenderness ratings of 10 major muscles from Bos indicus and Bos taurus cattle. J. Anim. Sci. 73:3333-3340. https:// doi.org/10.2527/1995.73113333x.

Smith, G. C., Z. L. Carpenter, H. R. Cross, C. E. Murphey, H. C. Abraham, J. W. Savell, G. W. Davis, B. W. Berry, and F. C. Parrish, Jr. 1985. Relationship of USDA marbling groups to 
palatability of cooked beef. J. Food Quality. 7:289-308. https://doi.org/10.1111/j.1745-4557.1985.tb01061.x.

Smith, G. C., J. W. Savell, H. R. Cross, Z. L. Carpenter, C. E. Murphey, G. W. Davis, H. C. Abraham, F. C. Parrish, Jr., and B. W. Berry. 1987. Relationship of USDA quality grades to palatability of cooked beef. J. Food Quality. 10:269-286. https://doi.org/10.1111/j.17454557.1987.tb00819.x.
USDA-AMS. 2020. National daily boxed beef cutout and boxed beef cuts - negotiated sales - PM. https:/usda.library. cornell.edu/concern/publications/9880vq97f?locale=en. (Accessed 8 December 2020.)

Vierck, K. R., J. M. Gonzalez, T. A. Houser, E. A. E. Boyle, and T. G. O'Quinn. 2018. Marbling texture's effects on beef palatability. Meat Muscle Biol. 2:142-153. https://doi.org/10. 22175/mmb2017.10.0052. 